\title{
Inter-gender interaction and communication in ultimatum games
}

\author{
Nikolaos Georgantzís \\ University of Reading, UK \& LEE - Universitat Jaume I, Spain \\ Despoina Parasyri \\ LEE - Universitat Jaume I, Spain \& Business and Environmental Technology Lab \\ (BETECO), Department of Environmental Engineering, Democritus University of Thrace, \\ 67100 Xanthi, Greece, e-mail:parasyri.despona@gmail.com, phone number: \\ (0030)6974466525

\section{Konstantinos Tsagarakis} \\ Business and Environmental Technology Lab (BETECO), Department of Environmental \\ Engineering, Democritus University of Thrace, 67100 Xanthi, Greece
}

\begin{abstract}
In this paper, we focus on bargaining within male-female pairs, the most pervasive partnership in humankind. We analyze data from an ultimatum game played by Greek subjects. Parallel to this, we introduce a one-way communication protocol according to which the responders can send short messages to the receivers, after making their decisions. The analysis shows that gender and message effects exist and that males are more effective bargainers.
\end{abstract}

Keywords: bargaining; communication; gender effect; message effect; ultimatum game

JEL Classification: C70; C90; C91; C92

\section{Introduction}

When focusing on partnerships of different genders, it is usually assumed that men are in charge while women have to bargain to receive their share (Meisenbach, 2010). In this paper, we study the bargaining ability and the role of each gender on both the responder and proposer positions in inter-gender pairs playing ultimatum games in the lab.

Concerning the role of gender in the ultimatum game, Eckel \& Grossman (2001) found that women appeared to be indifferent on the gender of the other player and that they were more generous than men. In the one-shot ultimatum game experiment conducted by Solnick (2001), the offers made to female players by both sexes were lower and the responders of both sexes 
intended to accept lower offers when facing female proposers. Moreover, in the literature there is evidence (Sutter et al., 2009) that in pairs of the same gender there was much more competition and retaliation and thus lower efficiency than in mixed-gender pairs. Concerning the influence of gender pairing, Ben-Ner et al. (2004) find that women give significantly less to women than to men and persons of unknown gender. Furthermore, women paired with women almost never fail to reach an agreement, which is interpreted as solidarity (Eckel \& Grossman, 2001). In our experiment we try to observe the behavior of Greek subjects on the aforementioned topics.

In this study, we focused on an ultimatum game between different genders, giving the responders the possibility to send a short open-type message to the proposers expressing their feelings about the offer they received after submitting their decision. Although there was no limitation at the length of each message, the participants were instructed at the beginning of each session to keep them short and compendious. We chose to insert virtual communication into our experiment because we wanted to compare the changes, if any, it produces in the subjects' behavior between the pre- and the post-message stage. As Winter \& Zamir (1997) state, the proposers adapt their offers to the responders' rejection and the responders adapt their rejections to the proposers' behavior.

The innovation of the current study is that there were used only pairs of different gender aiming to observe potential gender differences emerging when players are faced with the opposite gender. Furthermore, the introduction of communication between players in combination with the above structure makes this design unique, given the fact that very few bargaining experiments have been conducted under this scenario.

\section{Experimental design}

The results reported here were obtained from fourteen 60-period sessions of an ultimatum game played by 104 undergraduate students. In each session, the subjects were assigned the role either of the proposer or the responder according to their gender. Yet, subjects of the same gender had the same role throughout each session. Every participant was provided with written instructions. The experiment was designed and executed using the z-Tree software (Fischbacher, 2007).

In each period, the proposer's task was to place an offer of $€ X$, which could be any amount between $€ 0$ and $€ 20$, in steps of $€ 0.1$. Random proposer-responder pairs were formed 
within fixed, stable and independent, matching groups. The subjects were located in the same room but were unaware of the subject with whom they were to bargain. A responder who was randomly selected to be matched with a proposer received an offer and was called to accept or reject it. In the case of acceptance, the responder gained $€ X$ and the proposer $€ 20-X$. Otherwise, they both earned nothing. In order to prevent cumulative wealth effects, subjects were paid according to their earnings in one period randomly specified at the end of the session. Furthermore, due to limitation of funding only $80 \%$ of the subjects, randomly chosen in each session, were paid according to this rule and this was announced to them beforehand.

Every session included 4 stages depending on the role of each gender in the game as well as the presence or absence of communication and had the structure presented in Table 1. As presented in this Table, all the female subjects were entering in the experiment with the role of proposer for 30 rounds (15 with and 15 without communication) while for these rounds the male subjects had the role of responder. For the rest 30 rounds these roles were reverse. We followed this pattern of role changing in order to prevent any potential learning behavior. The female subjects had always the role of proposer at the beginning of the experiment and after the completion of the first 30 rounds they never returned to this role. As a consequence they never had the opportunity to make biased offers based on their former experience on both roles. The same applies to male subjects with were always had the role of responder at beginning of the experiment.

In the stages with communication the proposers were not allowed to respond to the message sent by the responders. In order to avoid ordering effects, the subjects were put in the above sub-sessions at random. We adopted this kind of experimental design in order to search for potential effects that the messages would have on the participants' behavior in the subsections with communication while in the same time searching for an impact of the message in the sub-sections without communication when the latter were conducted after the message subsections. Because participants' behavior could be affected by the short time between subsessions, we made sure to have alternations in the sequence of the sections with and without communication in order to minimize this effect.

\section{Results and Discussion}

Tables 2 and 3 present the mean values of the proposed amounts of money, the earnings of the proposers as well as the responders calculated on the basis of successful transactions and the percentage of accepted offers by subject role and gender. As Table 2 shows, there is an increase of $€ 1.49$ in offers in the message-based sub-sessions, and a decrease of $€ 0.43$ in the amounts 
offered in the message-based sub-sessions in rounds with male proposers (Wilcoxon test, $p=0.007)$.

\subsection{Gender Effects}

The emergence of possible gender effects in the offers and earnings of subjects in sub-sessions with and without communication was checked with respect to either of the two roles.

All the earnings were calculated exclusively on the basis of the successful transactions. The results are presented in Table 4 .

\subsection{Message effects}

The existence of potential message effects was investigated in the amounts offered and in the subjects' earnings in sub-sessions with and without communication for both roles. In order to do so, we read and analyzed all the messages sent by the responders and we categorized them based on the offered amount demanded by the responder, the amount that he was receiving and his reaction when we wasn't getting the desired amount of money. The results of this analysis are reported in Table 5.

From the analysis of the messages was found that when the responders were receiving the desired amount of money they tended to encourage the proposer to continue offering them the same amount of money or they applauded the offer with expressions like "well done", "good offer”, "keep offering this amount” etc. On the contrary, when the offered amount was low and not acceptable they reacted by threatening the proposer of a possible further rejection of their offers if they don't increase the offered amount. Expressions like "I need more”, "this is a low offer", “you have to offer more” etc. were used.

In order to ensure that differences in offers across pre- and post-message sub-sessions are not attributed to other factors, such as learning, we also examined and rejected the existence of learning behavior across the experiment sub-sessions, by analyzing the string of offers from each subject.

Moreover, in order to analyze the acceptance or rejection decision with respect to gender roles and the presence (or absence) of messages, we used the following Probit model, in which the dependent variable is the participants' decision and it takes the value 1 for acceptance and the value 0 for rejection. The results are displayed in Table 6 .

The interpretation of findings in Table 6 produces the following conclusions:

1. An increase in offers will increase the probability of acceptance $(P>|z|<0.001)$.

2. Being a female increases the probability of accepting an offer $(P>|z|=0.045)$. 
3. The presence of post-decision messages increases the probability of accepting an offer $(P>|z|=0.007)$.

4. Being a female participant in the message-based sub-sessions decreases the probability of accepting an offer $(P>|z|=0.043)$.

\section{Conclusion}

It has been conjectured that women may be discouraged from making riskier choices, in male-female groups, because they are inhibited by culturally driven norms about the appropriate mode of female behavior which is avoiding risk (Booth \& Nolen, 2015).

As the analysis of the results has shown, gender does play a role in the amount of money offered in both types of sub-sessions (i.e. message-based and message-free) as on the one hand, male subjects, opted to offer more in the sub-sessions without communication, whereas on the other, females were more generous in the sub-sessions with communication. Although we cannot reach a definite answer on gender effects in competitive environments, our finding differ from those of other studies in which it was found that female subjects tend to reject offers more often and to make lower offers (García-Gallego et al., 2008; 2012). This generosity of the female subjects can be explained as a risk avoiding behavior given the fact that higher offers may reduce the level of rejection.

In addition, a message effect also occurs affecting the level of offers. Females appeared more prone to changing their attitude and increasing their offers, when being aware of the other player's intentions and wishes.

Hence, it is apparent that the female participants in our experiment have used negotiation in a less aggressive manner than the male ones, while at the same time insisting on their demands. However, there is no evidence that women negotiate better than men. To sum up, the overall effect of the presence of communication is positive for male subjects, increasing their profits and their willingness to accept an offer.

\section{References}

Ben-Ner, A., Kong, F., \& Putterman, L. (2002). Share and share alike? Intelligence, socialization, personality, and gender-pairing as determinants of giving.

Booth, A. L., \& Nolen, P. (2015). Can risk-taking preferences be modified? Some experimental evidence. CESifo Economic Studies, 61(1), 7-32.

Croson, R., \& Buchan, N. (1999). Gender and culture: International experimental evidence from trust games. American Economic Review, 89(2), 386-391.

Eckel, C., De Oliveira, A. C. M., \& Grossman, P. J. (2008). Gender and negotiation in the small: Are women (perceived to be) more cooperative than men? Negotiation Journal, 24(4), 429-445.

Eckel, C. C., \& Grossman, P. J. (2001). Chivalry and solidarity in ultimatum games. Economic Inquiry, 39(2), 171-188. 
Fischbacher, U. (2007). Z-Tree: Zurich toolbox for ready-made economic experiments. Experimental Economics, 10(2), 171-178.

García-Gallego, A., Georgantzís, N., \& Jaramillo-Gutiérrez, A. (2008). Ultimatum salary bargaining with real effort. Economics Letters, 98(1), 78-83.

García-Gallego, A., Georgantzís, N., \& Jaramillo-Gutiérrez, A. (2012). Gender differences in ultimatum games: Despite rather than due to risk attitudes. Journal of Economic Behavior and Organization, 83(1), 42-49.

Meisenbach, R. J. (2010). The female breadwinner: Phenomenological experience and gendered identity in work/family spaces. Sex Roles, 62(1-2), 2-19.

Solnick, S. J. (2001). Gender differences in the ultimatum game. Economic Inquiry, 39(2), 189200. doi: 10.1111/j.1465-7295.2001.tb00060.x

Sutter, M., Bosman, R., Kocher, M. G., \& van Winden, F. (2009). Gender pairing and bargaining-Beware the same sex! Experimental Economics, 12(3), 318-331.

Winter, E., \& Zamir, S. (2005). An experiment with ultimatum bargaining in a changing environment Japanese Economic Review, 56(3), 363-385. doi: 10.1111/j.14685876.2005.00329.x

\section{Tables}

Table 1. Stages of the experiment

\begin{tabular}{ccccc}
\hline Stages & Rounds & Proposer & Responder & Communication \\
\hline 1 & 15 & Female & Male & No \\
2 & 15 & Female & Male & Yes \\
3 & 15 & Male & Female & Yes \\
4 & 15 & Male & Female & No \\
\hline
\end{tabular}

Table 2. Mean values of offers, earnings and acceptance frequencies with male proposers

\begin{tabular}{lcccc}
\hline & Offers & Proposer earnings & Responder earnings & Acceptance \\
\hline Without message & 9.16 & 10.11 & 9.88 & $82.94 \%$ \\
With message & 8.73 & 10.05 & 9.93 & $72.05 \%$ \\
\hline Overall & 8.95 & 10.08 & 9.90 & $77.50 \%$ \\
\hline
\end{tabular}

Table 3. Mean values of offers, earnings and acceptance frequencies with female proposers

\begin{tabular}{lcccc}
\hline & Offers & Proposer earnings & Responder earnings & Acceptance \\
\hline Without message & 7.62 & 11.54 & 8.45 & $67.80 \%$ \\
With message & 9.11 & 10.25 & 9.84 & $75.64 \%$ \\
\hline Overall & 8.37 & 10.89 & 9.15 & $71.72 \%$ \\
\hline
\end{tabular}


Table 4. Gender effects

\begin{tabular}{lll}
\hline Findings & Without communication & With communication \\
\hline $\begin{array}{l}\text { Finding 1: There is a } \\
\text { gender effect on offers }\end{array}$ & $\begin{array}{l}\text { Higher amounts offered by } \\
\text { males }(p<0.001) .\end{array}$ & $\begin{array}{l}\text { Higher amounts offered by } \\
\text { females }(p<0.044) .\end{array}$ \\
$\begin{array}{l}\text { Finding 2: There is a } \\
\text { gender effect on earnings }\end{array}$ & $\begin{array}{l}\text { 1. Female proposers tended to } \\
\text { in sub-sessions without more than the male ones } \\
\text { communication }\end{array}$ & $\begin{array}{l}\text { No significant difference in the } \\
\text { earnings of both genders in the } \\
\text { 2ole of the proposer and } \\
\text { to earn more than females } \\
(p<0.001) .\end{array}$ \\
\hline
\end{tabular}

${ }^{*} p$ values referred to Mann-Whitney U test

Table 5. Message effects

\begin{tabular}{|c|c|c|}
\hline Findings & Female & Male \\
\hline 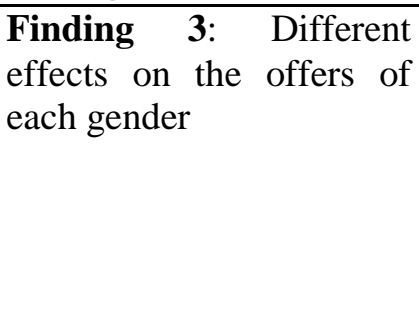 & $\begin{array}{l}\text { When proposers: increase of } \\
\text { offered amounts in message- } \\
\text { based sub-sessions compared } \\
\text { with those in message-free sub- } \\
\text { sessions }(p<0.001) \text {. }\end{array}$ & $\begin{array}{l}\text { When proposers: increase } \\
\text { in offers in the message- } \\
\text { based sub-sessions } \\
(p<0.001) \text { and decrease in } \\
\text { the amounts offered in the } \\
\text { message-based sub- } \\
\text { sessions ( } p=0.007) \text {. }\end{array}$ \\
\hline $\begin{array}{l}\text { Finding 4: A decrease in } \\
\text { the proposer's earnings in } \\
\text { message-based r sub- } \\
\text { sessions with female } \\
\text { proposers }\end{array}$ & $\begin{array}{l}\text { When proposers: earnings } \\
\text { decreased by } 11.17 \% \text { in the } \\
\text { message-based sub-sessions } \\
(p<0.001) \text { and increase of } \\
\text { acceptance. }\end{array}$ & $\begin{array}{l}\text { When proposers: the } \\
\text { decline of } 0.5 \% \text { in } \\
\text { earnings presented in } \\
\text { Table } 3 \text { is not statistically } \\
\text { significant }(p=0.873) \text {. }\end{array}$ \\
\hline $\begin{array}{l}\text { Finding 5: The messages } \\
\text { had a positive impact on } \\
\text { the responders' average } \\
\text { earnings with males in the } \\
\text { role of the responder } \\
\text { increasing their earnings. }\end{array}$ & $\begin{array}{l}\text { When messages sent by females: } \\
\text { no effect on their earnings } \\
(p=0.858) \text {. }\end{array}$ & $\begin{array}{l}\text { When messages sent by } \\
\text { males: increase in their } \\
\text { earnings }(p<0.001) \text {. }\end{array}$ \\
\hline $\begin{array}{l}\text { Finding 6: Female } \\
\text { responders failed to } \\
\text { convince male proposers } \\
\text { to give them the amount of } \\
\text { money they demanded }\end{array}$ & $\begin{array}{l}\text { Messages sent by the females } \\
\text { implied that they had no strategy } \\
\text { regarding their target of } \\
\text { acceptable offers. }\end{array}$ & $\begin{array}{l}\text { Male proposers managed } \\
\text { to receive almost always } \\
\text { the desired amount of } \\
\text { money, when sending } \\
\text { their message. }\end{array}$ \\
\hline
\end{tabular}

${ }^{*} p$ values referred to Wilcoxon test

Table 6. Probit results for the probability of acceptance

\begin{tabular}{ll}
\hline Decision & Coefficient Est. \\
\hline Offer & $0.14598^{* *}$
\end{tabular}




$\begin{array}{lc}\text { Female } & 0.14924^{*} \\ \text { Message } & 0.192^{* *} \\ \text { Female } \times \text { Message } & -0.2083^{*} \\ \text { Constant } & -0.6785 \\ \text { Observations Pseudo R2 } & 0.1282 \\ \text { Prob }>\text { chi2 } & <0.001\end{array}$

Offer: offered amount of money, Female: Female $=1$, Male=0, Message: 1 for the presence and 0 for the absence of messages, Female $\times$ Message: dummy product of gender and message, Significance: $* * 1 \%$, *5\% 